
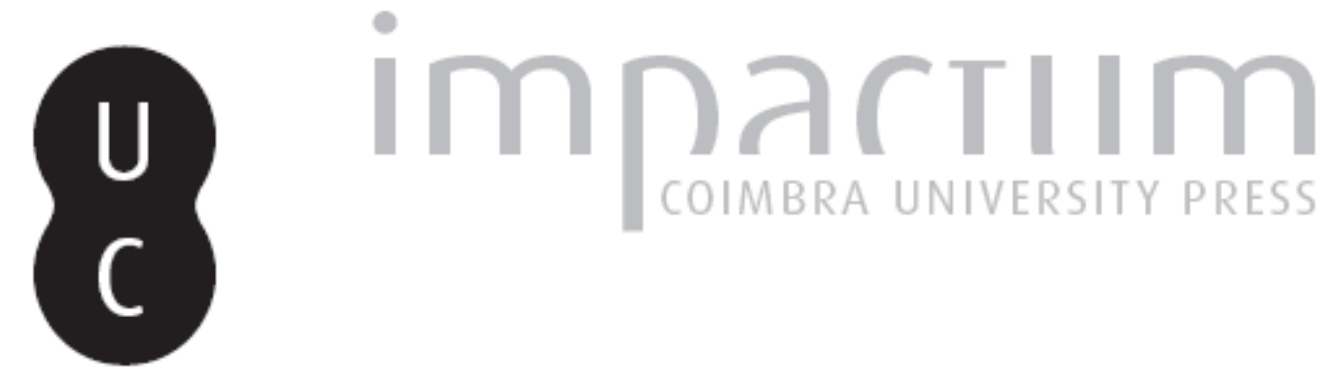

Un ensayo sobre la Historia considerada como poesía

Autor(es): $\quad$ Bermejo Barrera, J. C.

Publicado por: Imprensa da Universidade de Coimbra

URL persistente:

URI:http://hdl.handle.net/10316.2/43707

DOI:

DOI:https://doi.org/10.14195/2183-8925_25_16

Accessed : $\quad$ 26-Apr-2023 14:22:35

A navegação consulta e descarregamento dos títulos inseridos nas Bibliotecas Digitais UC Digitalis, UC Pombalina e UC Impactum, pressupõem a aceitação plena e sem reservas dos Termos e Condições de Uso destas Bibliotecas Digitais, disponíveis em https://digitalis.uc.pt/pt-pt/termos.

Conforme exposto nos referidos Termos e Condições de Uso, o descarregamento de títulos de acesso restrito requer uma licença válida de autorização devendo o utilizador aceder ao(s) documento(s) a partir de um endereço de IP da instituição detentora da supramencionada licença.

Ao utilizador é apenas permitido o descarregamento para uso pessoal, pelo que o emprego do(s) título(s) descarregado(s) para outro fim, designadamente comercial, carece de autorização do respetivo autor ou editor da obra.

Na medida em que todas as obras da UC Digitalis se encontram protegidas pelo Código do Direito de Autor e Direitos Conexos e demais legislação aplicável, toda a cópia, parcial ou total, deste documento, nos casos em que é legalmente admitida, deverá conter ou fazer-se acompanhar por este aviso.

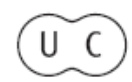



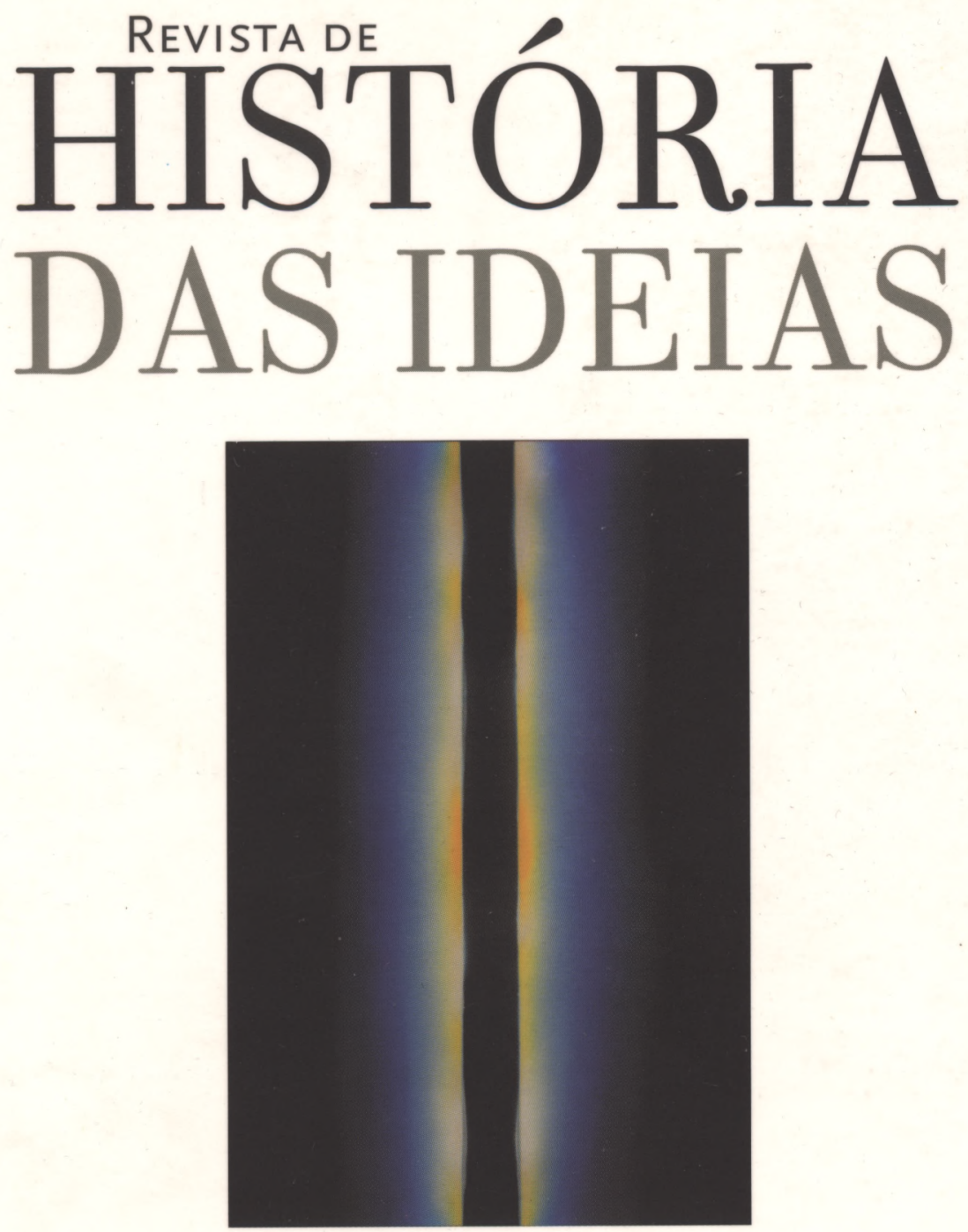

TOLERÂNCIAS, INTOLERÂNCIAS

\author{
Volume 25, 2004
}

INSTITUTO DE HISTÓRIA E TEORIA DAS IDEIAS

Faculdade de Letras da Universidade de CoImbra 


\section{UN ENSAYO SOBRE LA HISTORIA CONSIDERADA COMO POESÍA}

La simple lectura del título de este ensayo probablemente sonará a herejía, al ser leída por la mayor parte de los historiadores, ya que para ellos la historia es básicamente un tipo determinado de conocimiento que deberíamos asociar con la noción de ciencia, o bien un tipo de relato cuyo pariente más próximo deberíamos buscar en el ámbito del relato realista, y más concretamente en el terreno de la novela.

Por el contrario, consideramos a la historia como una de las formas de la poesía, de la que historiográficamente derivó, ya que es bien sabido que en el mundo griego la historia tomó el relevo de la épica como forma de dar cuenta del pasado. O bien, si nos salimos de la tradición occidental tendríamos un caso muy similar en la India, en la que la ausencia de la historiografía en la época precolonial se explica por el papel predominante de esa misma tradición épica. Establecemos consecuentemente este punto de partida por creer que en el seno de la historia sí que existe una función poética, que vendría dada por la triple naturaleza del discurso histórico, que esconde en su seno una contradicción fundamental en tres formas de hablar opuestas entre sí: a) - la descripción, b) - la evocación y c) - la expresión.

\footnotetext{
* Universidade de Santiago de Compostela.
} 
En el caso de la historia, para que un texto pueda ser catalogado bajo esa etiqueta genérica debe cumplir el requisito de abarcar estas tres dimensiones del lenguaje de forma complementaria y no excluyente. O lo que es lo mismo, no puede prescindir de ninguna de ellas, ni tampoco privilegiar excesivamente a una de las tres sobre las otras dos, ya que entonces el discurso de la historia perdería su naturaleza específica. Veamos, pues, en que consisten cada una de estas tres formas de hablar y como se articulan en el discurso histórico.

\section{Tesis $1^{2}$ : la historia es una descripción, pero no una mera descripción}

Que la historia posee un carácter descriptivo parece ser un hecho casi unánimemente admitido por la mayor parte de los historiadores y de los teóricos de la historia.

Parece claro que la historia siempre tiene que contar algo. Utilizando el vocabulario inglés podríamos decir que toda history es una story. Este hecho, que parece evidente al sentido común, ha sido elevado a categoría por todos aquellos historiadores que consideran que la historia es un relato. En este sentido tendríamos que distinguir dos situaciones. La primera de ellas correspondería al mundo greco-romano, en donde ello se admite sin más, y en donde el carácter narrativo de la historia no plantea ningún problema. El segundo caso se referiría al mundo contemporáneo en el cual, tras el nacimiento de la ciencia moderna se creó una situación en la cual parecía darse una contradicción entre el hecho de que el único paradigma gnoseológico válido fuese un paradigma no narrativo, como es el caso de la física newtoniana, que concibe un universo estático, y la pretensión de los historiadores europeos, a partir del nacimiento del historicismo alemán, de desarrollar un nuevo tipo de ciencia que, a su vez, fuese narrativa. Ese grupo de historiadores no podían prescindir de la narración, puesto que se dedicaban a la historiografía política en la que el curso de los acontecimientos está inexorablemente marcado por el tiempo.

Esta situación paradójica, a la que podríamos llamar la aporía del historicismo, vendría a ser aparentemente salvada por parte de los neokantianos alemanes (Dilthey, Winbdelband y Rickert), cuando estos filósofos intentan desarrollar una lógica dual de la ciencia. De acuerdo con ella, en el caso de Winbdelband, se pasaría a dividir a las ciencias 
en: nomotéticas, que explican mediante leyes, e ideográficas que serían aquellas que mediante la descripción consiguen proporcionarnos no exactamente una explicación si no una comprensión, Verstehen, concepto que desarrollarán sistemáticamente Dilthey y Rickert.

El Verstehen puede fundamentarse ontológicamente, como en el caso de Dilthey, en el que se establece una compartimentación metafísica entre el mundo de la naturaleza, asociado al espacio, y que debe ser explicado, y el mundo del espíritu, asociado al tiempo, que halla su manifestación por excelencia en la vida, en la que se manifiesta la conciencia. La conciencia es el lugar en el que reside la explicación, pero ella misma no puede ser explicada, ya que la explicación requiere la proyección hacia el exterior. La conciencia posee esa capacidad de proyectarse hacia el mundo, pero también está en su naturaleza el ser autoreflexiva, el poder orientarse hacia sí misma. Esa reflexividad es un componente fundamental del Verstehen, puesto que mediante él la conciencia da cuenta de sí misma, y es precisamente esa capacidad de dar cuenta de sí misma lo que define la naturaleza de la propia conciencia.

Pero también puede darse el caso de que el Verstehen no se fundamente ontológicamente, como ocurre con Rickert, quién no establece una contraposición entre espacio y tiempo, mundo externo y mundo interno, si no una antítesis entre concepto, que va unido al hecho y valor, que va unido a la propia conciencia. En el caso de Rickert la diferenciación entre ciencia natural y ciencia cultural no privilegiaría exclusivamente a la narración, puesto que los valores forman un sistema, y por ello es posible describirlos sincrónicamente, con lo que podremos concebir algunas ciencias culturales que estén libres de la tiranía del tiempo, que encadenaba a todos los historiadores historicistas.

No cabe duda alguna de la importancia que en su momento, y todavía ahora, poseen estas reflexiones, pero debemos destacar que ninguna de ellas señaló dos contradicciones fundamentales de la noción de descripción historiográfica, tanto en su vertiente diacrónica, como en su vertiente sincrónica. A saber que una descripción histórica pura es imposible debido a la ausencia del objeto descrito y a la imposibilidad de corroborar la descripción. Y por otra parte esa descripción histórica pura es igualmente imposible debido a la doble naturaleza de los enunciados históricos. Comenzamos por el segundo de estos puntos.

Es un hecho sabido en el ámbito de la lógica que Gottlob Frege estableció una distinción fundamental entre el Sinn (Sentido) y la 
Bedeutung (significado) de un enunciado. En la lógica aristotélica se parte del principio según el cual un enunciado es una estructura gramatical compuesta de un sujeto y un predicado que se refiere a un aspecto o situación del mundo, que es lo que constituye su referente. Si se da una coincidencia entre el contenido del enunciado y la situación del mundo el enunciado es verdadero, y si no es falso.

Pues bien, lo que deja claro Frege, tanto a nivel general, como aplicado a nuestro caso, es que los enunciados se refieren al mundo porque poseen significado, pero ese significado está inmerso en una red semántica constituida por el propio discurso en el que se inserta el enunciado, que es el que le da sentido. Así pues, los enunciados históricos se refieren a algo exterior, a una situación del mundo, pero también se refieren a sí mismos, al discurso que los crea y al historiador que los enuncia.

Ahora bien, en el caso de la historia tendremos una dificultad añadida. No solo será cierto en ella que un enunciado sólo adquiere sentido en el ámbito de un discurso, con lo cual tendríamos que admitir que no existen los enunciados observacionales, si no que además carecemos de referente externo. En efecto un acontecimiento histórico, en principio, tuvo lugar en el pasado, o lo que es lo mismo ya no existe. Incluso podríamos decir utilizando una idea de Arthur Danto, que nunca existió. Dice en efecto este filósofo en su libro Narration and Knowledge, que desde el momento en el que un historiador habla de un acontecimiento histórico, ese acontecimiento deja de existir como tal, porque la perspectiva de los protagonistas y la perspectiva del historiador son incompatibles. Así, por ejemplo, los combatientes de la batalla de Maratón no estaban participando en las "Guerras Médicas", ni los soldados que murieron en Verdún estaban en la "Primera Guerra Mundial". Esas guerras forman parte del discurso del historiador, pero no de la realidad histórica, que en sus momentos respectivos fue vivida de otra manera.

Los historiadores antiguos superaron esta dificultad mediante la figura del testigo. Un testigo es una persona que estuvo presente en el acontecimiento a investigar sea judicial o históricamente, y que puede transformar ese acontecimiento en relato. Es la propia corporeidad del testigo lo que garantiza la verdad de sus enunciados. Pero esa corporeidad debe estar avalada, de acuerdo con los sistematizadores del discurso historiográfico, como el retor Luciano - autor de un tratadito sobre Como se escribe la historia -, por dos condiciones: una física, y que es que el testigo haya estado materialmente en el lugar de los hechos y los haya 
podido observar, y otra moral, que consiste en que tenga la voluntad de decir la verdad, lo cual no siempre es fácil, ya que los historiadores, dice Luciano, están inclinados a adular a los poderosos.

A partir del nacimiento del historicismo la historia se adentra más en el pasado y deja de ser historia contemporánea, como lo era la historiografía antigua en muchos casos, y por ello desaparece la figura del testigo, para ser sustituida por el documento. Un documento es un discurso, y por lo tanto obra de un sujeto, que en el historicismo se concibe como testigo del acontecimiento, con lo cual se mantienen, aunque en un segundo plano, los requisitos que los historiadores clásicos veían como garantía de la verdad de la historia.

Sin embargo se introduce también una modificación y es que el documento, al ser considerado como un objeto, al igual que el monumento, pasan a ser considerados como los correlatos objetivos del acontecimiento. Y como ambos pueden ser siempre releídos o vueltos a contemplar, se sostiene que el papel que ellos cumplen es similar al que cumple el experimento en el campo de las ciencias físico-naturales, obviando una diferencia fundamental. El experimento reproduce el hecho objeto de la observación, el documento, por el contrario, no es el hecho observable, sino un discurso sobre un hecho, o lo que es lo mismo, una lectura de un acontecimiento que nosotros volvemos a releer. De acuerdo con la distinción de Frege, los enunciados del documento se refieren a un hecho, pero poseían un sentido en el ámbito del discurso de quien lo escribió. El historiador convierte esos enunciados en un hecho originario, olvidándose de que ya forman parte del discurso. Y sobre el sentido 1, el del documento, añade el sentido 2, el de su propio discurso.

$\mathrm{Si}$ los historiadores actúan de este modo es porque creen que lo que ellos están básicamente haciendo es describir, si son historiadores narrativos, o describir y analizar, si forman parte de aquel grupo de historiadores que quieren integrar la historia en el ámbito de las ciencias sociales. Tendríamos entonces que distinguir aquí: la acción que los historiadores llevan a cabo y el modo en el que los historiadores conceptualizan su labor. O lo que es lo mismo, tal y como dirían los antropólogos las versiones etic y emic de los hechos. En antropología los términos se utilizan para diferenciar la visión del indígena de la del propio antropólogo, que sería la versión científica. En nuestro caso el historiador es a la vez indígena y científico, lo que, paradójicamente, no contribuye a aclarar, si no más bien a confundir la situación. 
La contradicción se podría quizás aclarar si pasamos a considerar la segunda dimensión del lenguaje del historiador la evocación, y formulamos nuestra segunda tesis, según la cual:

\section{Tesis $2^{a}$ : la historia es una evocación, pero también algo más que una mera evocación}

La historia es una actualización de la ausencia, es decir, consiste básicamente en un proceso de evocación. Hay diversas formas de actualizar un fenómeno ausente. En el caso del mundo físico podemos llevar a cabo este proceso mediante signos o indicios que ponen de manifiesto la existencia en el pasado de un fenómeno que hoy en día nos resulta inobservable. Este sería el caso de la radicación cósmica de fondo, huella de Big Bang, que nos transmitiría el recuerdo de un acontecimiento ocurrido hace 15.000 millones de años. También en el mundo físico podemos deducir la presencia de un acontecimiento en el pasado a partir de un cálculo. Así, por ejemplo, conociendo la órbita de un cometa podremos deducir su presencia cerca de la Tierra hace cientos o miles de años.

Pero estos no son los casos que ahora nos interesan, ya que en el caso de la historia, de lo que se trata es de evocar a personas que vivieron en el pasado, junto con el mundo en el que desenvolvieron su actividad. A lo largo del devenir histórico las sociedades humanas han tenido diferentes formas de actualizar la ausencia. Durante el pasado siglo E.B. Tylor en su libro Cultura Primitiva, sostuvo la teoría según la cual las creencias de la inmortalidad del alma acerca de los seres míticos en general derivarían de la creencia más generalizada en los espíritus, o en la aparición de las almas de los antepasados difuntos. En la actualidad esta teoría no se considera válida y sólo grupos marginales practicantes del espiritismo, entre los que, en su momento, se encontraron prestigiosos historiadores del mundo antiguo, como Gilbert Murray y Eric D. Dodds, ambos catedráticos de filología griega de la universidad de Oxford, consideran que es posible hacer presentes las figuras de los antepasados.

Los historiadores más convencionales renuncian a evocar físicamente a los muertos, pero en cambio creen firmemente que es posible actualizar su presencia de dos maneras: mediante el cultivo de la memoria y gracias a la práctica de la historia. 
El cultivo de la memoria es un fenómeno consustancial al funcionamiento de la mente humana y se halla indisolublemente asociado al mantenimiento de nuestra identidad. Los neurólogos consideran que se dan tres fases sucesivas, reguladas por el funcionamiento del cerebro, que nos permiten llegar a la construcción de nuestro yo, o de nuestra identidad. La primera de ellas consistiría en el estado de vigilia, diferente al sueño o coma, sobre él el cerebro desarrolla su orientación en el mundo, y a partir de ella se construiría nuestra conciencia autobiográfica, o lo que es lo mismo, nuestra identidad.

A lo largo de nuestra vida, como señaló George Herbert Mead en su libro Mind, Self and Society, construimos nuestra identidad a partir de nuestra relación con los restantes miembros de nuestra familia y del resto de nuestro mundo social. En él construimos, junto a nuestra propia identidad, la noción de persona, que atribuimos al resto de nuestros contemporáneos. Una persona es un cuerpo, pero también una forma de hablar, de comportarse y del ver el mundo y de relacionarse con otras personas y con nosotros mismos. Nosotros somos capaces de disociar la noción de persona de la noción de cuerpo, y por ello, una vez que la persona fallece conservamos unas imágenes y unos recuerdos de la persona que asociábamos a un determinado cuerpo, lo que en muchas culturas dio lugar a la creencia en la inmortalidad.

Evocamos a una persona ausente, en primer lugar, por su nombre, a él asociamos su imagen y a ambos un conjunto de recuerdos, que está en constante proceso de reelaboración y en el que preconstruimos las relaciones que tuvimos con esa persona a lo largo de nuestra vida. Si esa persona fue conocida por varias personas presentes podremos reactualizar su ausencia mediante una serie de recuerdos compartidos. Pero para que ello sea posible es necesaria la presencia de lo que Alfred Schutz en su libro The Phenomenology of Social Action llamó el Mitwelt o mundo compartido de experiencias y vivencias comunes. Sólo si existe ese mundo podremos reactualizar colectivamente la ausencia de una o varias personas desaparecidas, actualización que puede apoyarse, además de en recuerdo y el diálogo, en el establecimiento de un sistema de rituales o fiestas conmemorativas o en la construcción de monumentos y la elaboración de objetos destinados a mantener el recuerdo.

Pero si es necesario señalar que esos recuerdos no son átomos que se transmitan incólumes en el tiempo, sino que están en un continuo proceso de construcción y de elaboración. La memoria es selectiva, no se puede 
recordar todo y además se reconfigura de una forma u otra en función de las circunstancias, personales o colectivas, de cada momento. Partiendo de este supuesto podremos afirmar que es posible actualizar la presencia de personas ausentes mientras perviva una comunidad que mantenga vivo su recuerdo. Cuando esa comunidad desaparezca el recuerdo de sus propios miembros y el de sus antepasados se hundirá en el olvido.

En este sentido el cultivo de la memoria por parte de los historiadores será posible en tanto que se cultive la historia oral y con personas y acontecimientos pertenecientes a un pasado próximo, a las que podamos llegar con nuestros recuerdos, y sobre todo con las que podamos tener un Mitwelt, un mundo común. Si se trata de un pasado lejano y de mundos históricos ajenos al funcionamiento de la memoria ya no será posible.

Sin embargo los historiadores gustan de ejercer la función de mnémones, esos antiguos magistrados griegos encargados de administrar el recuerdo. Para lograrlo recurren a una argucia verbal, al designar a la historia como memoria de una sociedad. En realidad se trata de una metáfora: la historia es como si fuese la memoria de nuestra sociedad, pero de una metáfora peligrosa y engañosa, ya que esa memoria no surge de una experiencia compartida, si no de un discurso que los historiadores imponen con mayor o menor éxito.

La historia es una ficción verbal. Es un discurso acerca del pasado que por casualidad vamos a considerar en este momento como un pasado remoto. En ese discurso el historiador construye un relato, que normalmente irá acompañado por diferentes tipos de explicaciones, y en el seno de ese relato habrá una determinada construcción del tiempo.

Los historiadores hacen una curiosa utilización de los tiempos verbales. Ya que hablan del pasado deberían casi exclusivamente utilizar el pasado, sin embargo ello no es siempre así y sus relatos actualizan el pasado hablando de él en tiempo presente con el fin de crear un mayor efecto de realidad. El historiador no habla como transmisor de un recuerdo si no como narrador de unos acontecimientos y un mundo en el que parece estar presente. Tiene la confianza de que puede hablar así porque, razonando de un modo incorrecto, creen que si los documentos del pasado, o sus monumentos, están presentes ahora, también estará presente consecuentemente el pasado mismo. Sin embargo es evidente que ello no es así, puesto que evidentemente las personas y el mundo social que crearon esos documentos están definitivamente desaparecidos. 
Pero el historiador, además de creer que puede actualizar el pasado mediante esta confusión un tanto ingenua, adquiere también cierta seguridad gracias a que es consciente de que él no es un evocador del pasado sin más. No sólo tiene los documentos que le acompañan sino también un método que le permite desarrollar su estudio. Este método, aprendido en las instituciones educativas es además un producto social que surge de una experiencia compartida, de un Mitwelt, con lo cual se da otra concordancia más que le permitiría establecer un paralelo con el mundo de la memoria.

Ese método da seguridad por dos razones. En primer lugar porque es compartido efectivamente por un grupo social - y un componente fundamental de la noción de verdad es el consenso - y en segundo lugar porque se asimila al método que garantiza la verdad en el mundo europeo moderno y contemporáneo, a la ciencia. El historiador nos puede decir, en efecto que él procede racionalmente en sus criterios de selección, lectura y análisis de sus documentos, procedimientos además avalados por el consensu omnium, con lo cual trabaja sobre cimientos firmes. Lo que oculta es que la historia, además de análisis de documentos, es también un discurso, una construcción dotada de sus propias reglas en sus formas de organización interna, reglas que pueden llegar a condicionar la lectura y la selección de la propia documentación.

Todo el trabajo preliminar de la investigación histórica tiene que desembocar en una fase de síntesis o exposición que no necesariamente todos los historiadores están capacitados para llevar a cabo, pero que, aunque sea una minoría, condiciona la investigación histórica de la totalidad de los cuerpos sociales de los grupos de investigación histórica. En esa fase toda la documentación, toda la información disponible, se pone al servicio de la reconstrucción histórica y esa reconstrucción no sería posible si todos esos datos obtenidos por procedimientos racionales, sistematizables y previsibles, no se subordinan a una totalidad superior, que Jean F. Lyotard llama metarrelato, o la que Frank Ankermsmit en su Narrative Logic, llama sustancia narrativa.

La sistematización y subordinación de toda esa información crea un efecto literario que suele llamarse el efecto de lo real, que también puede lograrse en la novela realista o en la ficción cinematográfica, y parte de ese efecto es la capacidad de evocación, asumida por historiadores románticos como Jules Michelet que pretendía a través de la historia volver a dar vida a los muertos de la historia de Francia, y no asumida o 
negada por ignorancia por parte de otros muchos historiadores que pretenden trabajar bajo el paradigma de la ciencia.

Entre el cultivo de la memoria y el manejo de la historia hay, sin embargo, una diferencia fundamental. Y es que el cultivo de la memoria forma parte de la experiencia inmediata vivida, mientras que el manejo de la historia requiere un proceso de aprendizaje y el desarrollo de una cierta capacidad de abstracción. La ausencia de la experiencia vivida la suple el historiador confundiendo el Mitwelt del pasado con el Mitwelt del presente. Una comunidad sabe que un recuerdo es verdadero porque lo comparte y ha formado parte de las vidas de sus miembros. El historiador espera que los lectores de sus libros o los alumnos que están destinados a aprender su manual asuman y compartan sus ideas en el presente, aunque esas ideas no están en su experiencia. Lo que sí está en su experiencia es el mundo presente en el que todos viven. Si se consigue desarrollar un consenso en él, si se consigue tener un ámbito de creencias compartidas, entonces estaremos seguros de estar en posesión de algún tipo de verdad.

No podemos vivir el pasado, sólo podemos recordarlo con nuestros sentimientos, o hablar de él. La memoria es una manera de sentir y de hablar. La historia es una manera de hablar que intenta inducir unas determinadas formas de sentir gracias al control de los sistemas educativos y de los medios de comunicación. La memoria pertenece al mundo de la experiencia inmediata, la historia no. Los recuerdos se tienen o no se tienen, la historia es necesario aprenderla y se requiere medios disuasorios para lograr el convencimiento y el consenso. $Y$ esos medios son, como hemos visto, las apelaciones a la materialidad de los documentos y a la existencia del método histórico, avalados por la autoridad de las instituciones educativas, y en último término por la existencia del propio estado-nación.

La historia es, pues, una evocación, como la memoria. Si la historia no poseyese la capacidad de evocación no podría desarrollar la capacidad de convicción, de persuasión, pero es también algo más que una evocación socialmente, en tanto que se trata de una evocación artificial, inducida, e intelectualmente, en tanto que se trata de una mezcla de la capacidad de evocación con procedimientos de discusión y análisis racional que poseen rasgos en común con las formas de razonamiento científico. Hay algo, sin embargo, que aleja a la historia del seguro camino de la ciencia, como gustaba de decir Inmanuel Kant, y ese algo es su componente expresivo, que será desarrollado en nuestra tercera tesis. 
Tesis $3^{\mathrm{a}}$ : la historia es una forma de expresión, pero también algo más que una forma de expresión

Solía decir Fustel de Coulanges a sus alumnos que cuando él hablaba no lo escuchasen a él, ya que quién en realidad les estaba hablando era el propio pasado. En la concepción historicista del saber histórico, el historiador es efectivamente un espejo que refleja limpiamente las formas del pasado y la mirada del historiador es similar a la mirada de Dios. No es que Ranke pretendiese usurpar las funciones de la divinidad, pero sí que es cierto que pensaba que la mirada del historiador, como la mirada de Dios, posee una visión panóptica, limpia y neutral.

Michel Foucault puso en su momento de manifiesto en Surveiller et Punir como el panoptismo es un proyecto de poder y un proyecto de control. La omnipresencia y la omnisciencia, atributos de Dios en muchas religiones, como ha observado Raffaele Pettazoni en su libro La omniscienza di Dio, son instrumentos fundamentales de control que Dios ha de ejercer sobre el mundo, por lo que podremos afirmar en primer lugar que la objetividad no es inocente y que la objetividad no es neutralidad.

Una cosa es la imagen que un historiador se hace de sí mismo y otra muy diferente lo que ese historiador es o hace. Podríamos decir, siguiendo a Karl Marx, en este caso, que también aquí es el ser lo que determina la conciencia y no la conciencia lo que determina al ser. Hoy en día resulta evidente a través del estudio de la obra de Ranke, por autores como Leonard Krieger (Leopold von Ranke) que Ranke poseía, como es evidente ideas políticas, morales y compartía muchos prejuicios sociales propios de su sociedad, de su clase social y de su época. Ese mundo de valores, como señalaba Heinrich Rickert en su libro Die Grenzen der naturwissechaftliche Begriffsbildung, se hacen presentes en la obra del historiador, quien selecciona sus temas, elige sus personajes y analiza los acontecimientos de acuerdo con su sistema de valores. Así, por ejemplo, la idea de que la historia es la política del pasado y la política es la historia del presente, clave del historicismo, ni forma parte de la realidad natural ni está escrita en los documentos, sino que es la clave con la cual selecciona Ranke la documentación y la trama de lectura que lo guía.

Del mismo modo la idea de que la política exterior tiene primacía sobre la política interior es solidaria de una concepción del estado que lo considera como órgano básico para llevar a cabo la guerra, que es la forma en la que el estado manifiesta toda su plenitud, y tampoco esa 
idea se expresa directamente en la documentación. Si seleccionásemos lo que los historiadores han venido pensando de las mujeres, los judíos o de las civilizaciones no occidentales, veríamos que tampoco esas ideas están inscritas ni en la realidad ni en los documentos, sino que forman parte de la visión del mundo de determinados historiadores del pasado. Si eso es cierto de Ranke y los historicistas, pensemos lo diferente que puede ser uno de nuestros "antepasados historiográficos" como Tucídides en sus ideas sobre el hombre y la mujer, la esclavitud o la barbarie.

El historiador se expresa. Expresa su visión del mundo, sus valores y sus sentimientos, lo que resulta muy evidente en historiadores nacionalistas o social y políticamente comprometidos, pero el historiador no es simplemente un ideólogo, un predicador o un poeta lírico, que aspira a exteriorizar su mundo interior. El historiador es una esfinge o un centauro, un híbrido, y no de hombre y animal, como esos seres mitológicos.

Es un híbrido porque se expresa describiéndose no a sí mismo si no a los demás, no a su propio mundo si no a un mundo que le es ajeno, y además no sólo no habla de sí mismo para conseguir expresarse, sino que además hace que otros hablen por él. Que por él hable el pasado a través de los documentos y mediante el método.

Da la impresión de que el historiador no tiene la capacidad de expresar sus propias ideas. Es bien sabido el lema que I. Kant colocó como emblema de su Crítica de la Razón Pura: de nobis ipsis silemus, no hablemos de nosotros mismo. El historiador, que casi nunca lee a Kant, ni a Sir Francis Bacon, de quien proviene el lema, actúa inconscientemente. Él no quiere hablar de sí mismo o de su grupo social. Si fuese consecuente podría dedicarse a las matemáticas, y hablar así de relaciones abstractas que nada tienen que ver con los valores y los sentimientos, a la física, y hablar así de la materia inorgánica, o a la zoología y hablar así de los animales. Pero no, él decide hablar de los hombres, ese objeto tan querido de los historiadores, como gustaban decir dos de los grandes: Marc Bloch en Le métier de l'Historien y Lucien Fevbre en sus Combates por la historia.

El problema es que si un ser humano habla de los hombres, aunque sea en plural, como siempre habrá que hacer, siguiendo el consejo de Marc Bloch, está hablando de sí mismo, y no cumple el precepto baconiano y kantiano. Ahora bien, la forma de hablar propia del historiador no consiste en hablar de sí mismo. El habla acerca de los demás pero utilizando un juego de espejos. El pasado no se refleja tal cual en el espejo de la mente del historiador, es por el contrario el historiador el que 
proyecta su imagen en el espejo del pasado, pero no para reconocerse directamente en él, si no para verse ocultado bajo otra forma, como si fuese un palimpsesto. En un palimpsesto bajo un texto aparente se esconde un texto oculto. En un libro de historia bajo el discurso referido al pasado se esconde otro discurso referido al propio historiador.

El historiador puede superponer los dos textos de forma simétrica o asimétrica. Los superpone de forma simétrica si realiza un procedimiento de asimilación, como el que se realizó con el mundo griego. Desde la antigüedad los romanos gustaron de identificarse con el pasado griego. Plutarco estableció paralelismos entre los grandes hombres griegos y romanos en sus Vidas paralelas y los emperadores romanos gustaron de identificarse con Alejandro Magno.

Durante la Edad Media se quiso revivir el Imperio Romano bajo la forma del Sacro Imperio Romano Germánico y los revolucionarios franceses quisieron resucitar las antiguas repúblicas ateniense y romana. En la época victoriana o en la Alemania Guillermina se pensaba que bajo la piel de un inglés o un alemán podría aparecer el cuerpo de un griego antiguo... Podría seguir enumerando así ejemplos de asimilación hasta el agotamiento, siguiendo con.la lectura de nuestro palimpsesto, aunque se podría decir que esas asimilaciones son cosas del pasado.

No obstante ello no es así, ya que también existe un procedimiento de asimilación asimétrica. De acuerdo con él lo que se busca no es la semejanza con el pasado, si no la diferencia, ya sea porque el pasado sirva como instrumentos de rechazo del presente, mediante la búsqueda del exotismo de Oriente, por ejemplo, o gracias a la supuesta vuelta a un mundo primitivo, en el que saldrían a la luz aquellos aspectos más auténticos y originarios de la naturaleza humana que el mundo civilizado habría suprimido o reprimido. En cualquier caso el Oriente exótico o el primitivo auténtico, al igual que el primitivo caníbal o promiscuo y sanguinario de la antropología victoriana son construcciones del propio mundo occidental y sirven a las necesidades expresivas, no del propio oriental o del supuesto primitivo, si no del propio hombre occidental.

Podríamos preguntarnos ¿Por qué el historiador pretende renunciar a hablar de sí mismo, y sin embargo es incapaz de dejar de hacerlo? La respuesta sería doble. Ello se debe, en primer lugar, a que la historia básicamente ha sido un discurso de dominación, de los miembros de la propia cultura del historiador y de los de otras culturas ajenas con las que ha entrado en relación de dominio, de sumisión o de colonización. 
En el mundo social parece darse de modo nítido esa ecuación entre el saber y el poder que tanto gustaba a Michel Foucault. Del mismo modo que para gobernarse a sí mismo es necesario construir una determinada imagen de nuestro yo, a la que intentaremos ajustar nuestra conducta. En el terreno social el control sobre la población es inseparable de una determinada serie de imágenes acerca de los seres que la componen, imágenes necesarias tanto para poder ejercer con eficacia la tecnología de la dominación como para justificarla por sí misma.

La historia es un discurso de dominación, pero no se formula a sí misma como tal, si no como un conocimiento casi perfecto de la realidad. No es posible una dominación si no existe el deseo de dominar, pero ese deseo casi nunca es reconocido como tal. No se gobierna por placer si no en función de un interés superior, ya sea ético o científico.

La ocultación del deseo en las formas de dominación y la ocultación que el historiador hace de sí mismo son dos procesos que poseen caracteres en común. En ambos casos se desarrolla una estrategia de enmascaramiento, se oculta lo subjetivo tras una máscara supuestamente objetiva, pero como lo subjetivo es la raíz de lo supuestamente objetivo, el deseo, expulsado por la puerta se cuela por la ventana. Sin embargo y al igual que ocurre con otros mecanismos de ocultación del deseo, como los que tienen lugar en el sueño, tal y como lo analiza Sigmund Freud, la irrupción del deseo se lleva a cabo en un mensaje cifrado, cuyas claves serían los mecanismos de condensación y de desplazamiento, o formulado con una terminología lingüística más actualizada, mediante el recurso constante a la metáfora y a la metonimia, dos instrumentos claves en el discurso histórico, tal y como pone de manifiesto la Metahistory de Hayden White.

$\mathrm{Al}$ igual que ocurre con el sueño, en el que la liberación del deseo pone fin a la historia onírica, en el caso de la historia muchos discursos y disputas historiográficas hallarían su fin si en vez de hablar de una forma supuestamente objetiva acerca de un pasado neutral, se sacasen a la luz las ideas, los valores o los gustos y las opciones de las personas que se trata de defender. Piénsese en debates como el caso de Melos en la Guerra del Peloponeso en el que historiadores alemanes e ingleses pretendieron dilucidar con una discusión jurídica y epigráfica el problema de la superioridad moral de Esparta o Atenas, del autoritarismo o de la democracia, de Alemania o de Inglaterra.

O piénsese también en el debate sobre los estamentos y las clases en el Antiguo Régimen, desarrollado entre los historiadores marxistas y 
antimarxistas. O en discusiones sobre el número de muertos del nazismo y sus campos de concentración o del estalinismo, o en el interés de algunas feministas en defender la existencia del matriarcado, etc.

Ahora bien, junto al proceso de represión del deseo, que genera la capacidad de contar historias, al igual que hace el sueño, existe también un componente más profundo cuando tratamos del problema de la expresión y el lenguaje de los historiadores. Y es que, en último término, la expresión es inevitable, podremos limitarla, regularla y liberarla, pero no suprimirla. Y ello es debido a que, al fin y al cabo, en historia seres humanos hablan acerca de otros seres humanos, que podrán ser con respecto a ellos próximos o remotos, pero que siempre poseerán una naturaleza común.

Por supuesto, tendrá que evitar el asimilarlos positiva o negativamente, tendrá que evitar el quitarles su voz, pero, aunque lo consiga en último término se encontrará con que entre todos ellos existe una raíz común, que no puede ser conocida a priori ni definitivamente, si no sólo parcialmente y a partir de la confrontación entre las diferentes personas y las diversas culturas.

Aunque el historiador lo quiera no podrá callar acerca de sí mismo, si lo intenta redactará palimpsestos en los que el pasado hablará por él y se daría entonces una situación de alienación muy curiosa. El historiador no quiere reconocerse a sí mismo directamente, quiere conocer un pasado, con el que se identifica aparentemente por razones altruistas y racionales, pero en el que, en el fondo, espera encontrarse a sí mismo, ya sea en su propia imagen, o a través de un juego de imágenes deformadas.

El historiador se hace de sí mismo una imagen épica. Héroe del conocimiento, desinteresado caballero que parte a la búsqueda del pasado, no por su propio interés ni en pos de ningún placer, si no únicamente orientado por el lejano resplandor de la verdad. Pero esa imagen no se corresponde, en modo alguno, con la realidad. El historiador, como cualquier ser humano, está movido por sus pasiones, lo mueve el ansia de reconocimiento de sus colegas y sus contemporáneos, cuando no la propia libido dominandi, un componente básico del homo academicus, tal y como ha analizado Pierre Bourdieu en el libro de ese título (Homo academicus). Y posee no sólo ideas morales y valores estéticos que condicionan su visión del pasado, si no también prejuicios que son constitutivos de su profesión, de su clase social, del mundo universitario y de su propia cultura. 
$\mathrm{Si}$, siguiendo el símil psicoanalítico, pretendemos que el historiador se libere de su falsa imagen épica y saque a la luz los deseos que lo constituyen tendría que dar tres pasos. En primer lugar tendría que reconocer que él, como todo historiador se expresa, expresa sus sentimientos, ideas, valores y prejuicios inevitablemente, utilizando siempre la coartada de los documentos y el método que enmascaran todos esos elementos tras la pantalla de la objetividad.

En segundo lugar tendría que reconocer que su misión es la de evocar el pasado. No evocarlo sin más, si no mediante una serie de instrumentos literarios y analíticos que le permiten representarlo o describirlo.

El discurso del historiador es un discurso híbrido. No se puede suprimir ninguno de los tres elementos que lo componen, ni privilegiar a ninguno de ellos sobre todos los demás. Si el historiador privilegiase radicalmente la expresión de sus sentimientos e ideas se convertiría en un poeta. Si privilegiase su capacidad de evocación se convertiría en un novelista. Si quisiese hacer una descripción neutral se convertiría en un naturalista, o en un biólogo, y si pretendiese explicar por leyes se convertiría en un físico. El historiador tiene que hacer las tres cosas a la vez, y por ello su labor no es estrictamente asimilable ni con la ciencia, ni con la narración literaria, ni con la poesía lírica.

Por el contrario la labor del historiador sería más asimilable a una poesía como la epopeya homérica que contiene a la vez: descripciones del mundo físico mediante una serie de imágenes, descripciones del mundo social, expresiones de sentimientos de todo tipo, y todo ello unido bajo una fuerte capacidad de evocación. Ello no quiere decir que propongamos abandonar la historia y volver a escribir epopeyas, cuya capacidad de movilización política es - por cierto - muy similar a la que posee la historiografía, si no resituar a la historia en relación con la ley comteana de los tres estadios.

Decía Auguste Comte en su Cours de Philosiphie Positive, en los tomos correspondientes a la "Physique Sociale", que la humanidad habría pasado por tres estadios: el religioso, el metafísico y el positivo, o científico, pudiendo cada uno de esos tres estadios sobrevivir en los siguientes. Pues bien, creo que, a la hora de caracterizar a la historia podría situarla como un claro ejemplo de supervivencia de los tres estadios comteanos, ya que posee caracteres en común con la religión, con la metafísica, que es una curiosa forma de hacer poesía en prosa y con la ciencia.

La historia posee en común con la religión el que responde a la necesidad de los seres humanos de trascender el presente, para lo que 
recurren a medios imaginarios. Decía Karl Jaspers en su Philosophy (I, II, III) que podríamos distinguir tres niveles en el análisis filosófico. El primero sería el nivel del Dasein o de los seres que carecen de conciencia y sólo poseen ser. El segundo sería la Existenz, propia de los seres conscientes que viven en el mundo social, y el tercero sería la Transzendent, en la que esos seres intentan superar su conocimiento del mundo físico y social mediante lo que él llama las cifras, o formas simbólicas que sirven para expresar sentimientos mediante imágenes que intentan superar los límites de nuestro conocimiento y nos ayudan, sin lograrlo, a intentar superar nuestra finitud.

En este sentido la historia trabaja con cifras. La historia intenta superar el paso destructivo del tiempo, al igual que el poeta épico con el cultivo de la memoria, con la elaboración del discurso que intenta actualizar un pasado perdido y dar sentido a la vida humana en un universo que, por sí mismo, carece de sentido. La historia intenta de este modo superar tanto las limitaciones como la banalidad del tiempo presente recreando otra serie de mundos posibles, que, una vez desaparecidos, vuelven a ser actuales. La historia intenta fundamentar la esperanza en un mundo en el que la esperanza no tiene ningún lugar y otorgar un orden racional a un universo en el que la razón no es más que un epifenómeno de la vida. En todos esos sentidos la historia es profundamente religiosa.

Los historiadores no fundan iglesias, pero sí poseen instituciones propias de los que profesan la disciplina y, como los demás sacerdotes del mundo, aspiran a que sus doctrinas sean enseñadas y se instauren social y políticamente. Frente a esa religión institucionalizada, como frente a todas las religiones, deberíamos defender el valor de la religiosidad libre, entendiendo que la religión no es más que la expresión de un deseo y que los mundos imaginarios que las diferentes religiones han venido desarrollando no forman parte de la realidad.

La religión es la manifestación de un deseo que aspira a realizarse, a objetivarse. La historia como realización de deseos, que se plasman en mundos imaginarios y desaparecidos, también sería aceptable si la entendemos como un intento de trascender el mundo presente, en sus aspectos sociales y políticos, ya que el mundo físico - en contra de lo que secularmente han venido intentado las religiones - no se puede trascender.

Pero, de acuerdo con Comte, la religión fue siendo superada por la metafísica. La metafísica es un intento de penetrar en la esencia del mundo más allá del conocimiento aparente y de las opiniones establecidas. 
La metafísica no crea seres míticos ni dioses imaginarios, si no que trabaja con nociones abstractas. Pero, en último término, el fin de la metafísica, como el fin de la religión es intentar dar sentido a la vida humana en el ámbito del universo. Un intento desesperado ya que el universo no tiene sentido, somos nosotros los que lo ponemos en él.

La metafísica, decía Arthur Schopenhauer en Die Welt als Wille und Vorstellung va por un camino recto al mismo lugar al que la religión llega por un camino sinuoso. La metafísica, como señala Martin Heidegger, posee muchos puntos en común con la poesía. Lo que la primera intenta lograr mediante conceptos lo logra la segunda mediante imágenes.

La historia posee en común con la metafísica y la poesía su intención de llegar al conocimiento de la condición humana superando las limitaciones del mundo inmediato mediante la capacidad de evocación, unida al uso de conceptos y, en menor medida de imágenes. Los metafísicos no fundan iglesias, si no escuelas. Pero, al igual que la religión, la metafísica no es más que un intento desesperado de objetivar el deseo.

Por último la historia poseería en común con la ciencia el uso de instrumentos de discusión y análisis racionales puestos al servicio de un conocimiento de la realidad. Pero ese conocimiento, en el caso de la historia, estará fuertemente condicionado por la supervivencia de sus componentes metafísicos y religiosos.

La historia es la evocación de una ausencia, la expresión finita de un deseo que aspira a ser infinito, la descripción imperfecta de mundos desaparecidos. La historia es el intento de superar el paso devastador del tiempo, de trascender las limitaciones de nuestro mundo social y político, de aspirar a la realización de deseos. La historia es una extraña e híbrida forma de poesía que puede ser aprendida, discutida y compartida. Una forma de pensar y de expresarnos que no puede ser abandonada en el momento presente, porque frente a ella aún no tenemos alternativas. Homero ya no puede vivir en la sociedad postindustrial y del conocimiento, pero esa sociedad aún tiene mucho que aprender de él. En primer lugar porque aún sobreviven en otros lugares fuera de esa sociedad mundos más parecidos al homérico que al mundo presente, y en segundo lugar, y sobre todo, porque nuestro mundo, como todos los demás que han sido es radicalmente incapaz de dar cuenta de sí mismo. 
Bibliografía

ANKERSMIT, Frank R. - Narrative Logic, La Haya, Martinus Nijhoff, 1983.

BERMEJO BARRRERA, J.C. - ¿Qué es la historia teórica?, Madrid, Akal, 2004.

BLOCH, Marc - Apologie por l'Historie ou Métier d'historien, Paris, Armand Colin, $8^{\text {a }}$ ed., 1974.

BOURDIEU, Pierre - Homo academicus, Paris, Minuit, 1984.

COMTE, Auguste - Physique Sociale. Cours de Philosophie Positive. Leçons 46 à 69, Paris, Hermann, 1975 (1839-1842).

DANTO, Arthur D. - Narration and Knowledge, New York, Columbia Univ. Press, 1985 ( $1^{a}$ ed. 1968).

DILTHEY, Wilhem - Introducción a las ciencias del Espíritu, Madrid, Alianza, 1980 (1883).

FEVBRE, Lucien - Combates por la Historia, Barcelona, Ariel, 1970.

FOUCAULT, Michel - Surveiller et Punir. La naissance de la Prison, Paris, Gallimard, 1975.

JASPERS, Karl - La Fe filosófica ante la revelación, Madrid, Gredos, 1968 (1962).

JASPERS, Karl - Philosophy, I, II, III, University of Chicago Press, 1969 (1932, 1948, 1956).

KANT, Inmanuel - Kritik der reinen Vernunft, en Werke, Darmstad, Wissenschafttliche Buchgesselschaft, 1983.

KRIEGER, Leonard - Leopold von Ranke: The meaning of History, Chicago, Chicago University Press, 1977.

MEAD, George Herbert - Mind, Self and Society, Chicago, University of Chicago Press, 1934.

PESTAZONNI, Rafaelle - L'onniscienzia di Dio, Torino, Einaudi, 1955.

RICKERT, Heinrich - Die Grenzen der naturwissenchaftlichen Begriffsbildung, Tübingen, J.C.B. Mohr, 1921.

SCHOPENAHUER, Arthur - Die Welt als Wille und Vorstellung, en Werke, Darmstad, Wissenschafttliche Buchgesselschaft, 1968.

SCHUTZ, Alfred - The Phenomenology of the Social World, Northewester University Press, 1967.

TYLOR, Edward Burnett - Cultura primitiva, I y II, Madrid, Ayuso, 1977 (1871).

WHITE, Hayden - Metahistory. The historical Imagination in Nineteenth-Century Europe, Baltimore, John Hopkins Univ. Press, 1977.

WINDELBAND, Wilhelm - An Introduction to Philosophy, London, Fischer Unwin, 1921 (1914). 